\title{
Preclinical Evaluation of an Engineered Single-Chain Fragment Variable-Fragment Crystallizable Targeting Human CD44
}

Philipp Diebolder ${ }^{1,2}$, Cedric Mpoy ${ }^{1}$, Jalen Scott ${ }^{1}$, Truc T. Huynh ${ }^{1,3}$, Ryan Fields ${ }^{2,4}$, Dirk Spitzer ${ }^{2,4}$, Nilantha Bandara ${ }^{1}$, and Buck E. Rogers ${ }^{1,4}$

${ }^{I}$ Department of Radiation Oncology, Washington University School of Medicine, St. Louis, Missouri, ${ }^{2}$ Department of Surgery, Washington University School of Medicine, St. Louis, Missouri; ${ }^{3}$ Department of Chemistry, Washington University, St. Louis, Missouri; and ${ }^{4}$ Siteman Cancer Center, Washington University School of Medicine, St. Louis, Missouri

Glycoprotein CD44 and alternative splice variants are overexpressed in many cancers and cancer stem cells. Binding of hyaluronic acid to CD44 activates cell signaling pathways, inducing cell proliferation, cell survival, and invasion. As such, CD44 is regarded as an excellent target for cancer therapy when this interaction can be blocked. In this study, we developed a CD44specific antibody fragment and evaluated it for imaging CD44positive cancers using PET. Methods: A human single-chain fragment variable (scFv) was generated by phage display, using the extracellular domain of recombinant human CD44. The specificity and affinity of the scFv-CD44 were evaluated using recombinant and tumor cellexpressed CD44. Epitope mapping of the putative CD44 binding site was performed via overlapping peptide microarray. The scFv-CD44 was reformatted into a bivalent scFv-Fc-CD44, based on human $\mathrm{IgG}_{1}$-fragment crystallizable $(\mathrm{Fc})$. The scFv-Fc-CD44 was radiolabeled with ${ }^{64} \mathrm{Cu}$ and ${ }^{89} \mathrm{Zr}$. The purified reagents were injected into athymic nude mice bearing CD44-positive human tumors (MDA-MB-231, breast cancer, triple-negative). Biodistribution studies were performed at different times after injection of $\left[{ }^{64} \mathrm{Cu}\right] \mathrm{Cu}-\mathrm{NOTA}-\mathrm{scFv}-\mathrm{Fc}-\mathrm{CD} 44$ or $\left[{ }^{89} \mathrm{Zr}\right] \mathrm{Zr}-\mathrm{DFO}-\mathrm{scFv}-\mathrm{Fc}-\mathrm{CD} 44$. PET/CT imaging was conducted with [ $\left.{ }^{89} \mathrm{Zr}\right] Z \mathrm{Zr}-\mathrm{DFO}-\mathrm{scFv}-\mathrm{Fc}-\mathrm{CD} 44$ on days 1 and 7 after injection and compared with a scFv-Fc control antibody construct targeting glycophorin A. Results: Epitope mapping of the scFv binding site revealed a linear epitope within the extracellular domain of human CD44, capable of blocking binding to native hyaluronic acid. Switching from a monovalent ScFv to a bivalent scFv-Fc format improved its binding affinity toward native CD44 on human breast cancer cells by nearly 200 -fold. In vivo biodistribution data showed the highest tumor uptake and tumorto-blood ratios for [ ${ }^{89} \mathrm{Zr}$ ]Zr-DFO-scFv-Fc-CD44 between days 5 and 7 . PET imaging confirmed excellent tumor specificity for [ $\left.{ }^{89} \mathrm{Zr}\right] \mathrm{Zr}$-DFOscFv-Fc-CD44 when compared with the control scFv-Fc. Conclusion: We developed a CD44-specific scFv-Fc construct that binds with nanomolar affinity to human $\mathrm{CD} 44$. When radiolabeled with ${ }^{64} \mathrm{Cu}$ or ${ }^{89} \mathrm{Zr}$, it demonstrated specific uptake in CD44-expressing MDA-MB231 tumors. The high tumor uptake ( $56 \%$ injected dose/g) warrants clinical investigation of $\left[{ }^{89} \mathrm{Zr}\right] \mathrm{Zr}-\mathrm{DFO}-\mathrm{scFv}-\mathrm{Fc}-\mathrm{CD} 44$ as a versatile PET imaging agent for patients with CD44-positive tumors.

\footnotetext{
Received May 13, 2020; revision accepted May 19, 2020.

For correspondence or reprints contact: Buck E. Rogers, Washington University School of Medicine, 4511 Forest Park Blvd., Suite 411, St. Louis, MO 63108.

E-mail: rogers@radonc.wustl.edu

Published online Jun. 8, 2020.

COPYRIGHT @ 2021 by the Society of Nuclear Medicine and Molecular Imaging.
}

Key Words: immuno-PET; CD44; scFv-Fc; ${ }^{89} \mathrm{Zr} ;{ }^{64} \mathrm{Cu}$

J Nucl Med 2021; 62:137-143

DOI: 10.2967/jnumed.120.249557

C D44 is a heavily glycosylated transmembrane receptor and plays key roles in adhesion to the extracellular matrix, signal transduction, and cytoskeleton remodeling. CD44 is one of the major receptors for the glycosaminoglycan hyaluronic acid (HA), which is an abundant part of the extracellular matrix. The standard form of CD44 is encoded by 9 constant exons that are spliced together with exons $1-5$, forming the extracellular domain (1). Furthermore, CD44 is one of the most studied glycoproteins in cancer and is overexpressed by various solid tumors and hematologic malignancies, whereas different splice variants of CD44 have been identified in squamous cell carcinomas (2). Many cancer-related studies have used monoclonal antibodies for targeting extracellular regions on standard CD44 (exons 1-5) and CD44 variant 6 (exon 10). Both the standard form and splice variants have been associated with tumor progression, metastasis, and disease progression, making CD44 a promising target in cancer therapy (3).

Disruption of the CD44-HA interaction is believed to be the underlying mechanism of CD44-targeted cancer therapeutics. Bivatuzumab, a humanized monoclonal antibody directed against the variable region $\mathrm{CD} 44$ variant 6 does not appear to block the interaction with HA. Therefore, it was conjugated to the antimicrotubule drug mertansine to induce a direct cytotoxic effect on internalization. However, subsequent phase I clinical trials were halted because of severe, at times lethal, toxic epidermal necrolysis (4). RG7356, a humanized monoclonal antibody targeting the constant region of the extracellular domain of all CD44 isoforms, binds to an epitope near the HA-binding region and has been shown to have antitumor activity as a monotherapy in mouse xenografts that are CD44-positive and HA-positive but not in xenografts that are CD44-positive and HA-negative (5). Since CD44 is also expressed in human epithelial tissues such as the lung, skin, and mammary gland, it was hypothesized that radiolabeled RG7356 could be used to determine the in vivo expression of CD44 by PET imaging. This ability would be critical for the development of CD44-targeted, antibody-based cancer therapies.

Consequently, RG7356 was radiolabeled with ${ }^{89} \mathrm{Zr}$ and evaluated both preclinically $(6)$ and in cancer patients $(7,8)$. Tumor 
targeting was confirmed in mice bearing CD44-positive tumor xenografts but was also found in CD44-expressing tissues, such as the spleen and bone marrow of cynomolgus monkeys (6). A dose escalation study of RG7356 in patients with CD44-positive solid tumors demonstrated excellent tolerability and modest efficacy, with disease stabilization in $21 \%$ of the patients $(8) .{ }^{89} \mathrm{Zr}$ labeled RG7356 was used in a subset of these patients and showed tumor targeting when doses of more than $200 \mathrm{mg}$ of RG7356 were given. Further analysis of these data demonstrated how $\left[{ }^{89} \mathrm{Zr}\right] \mathrm{Zr}$ DFO-RG7356 could be used to quantify dose-dependent uptake in normal tissues (7).

In general, antibody fragments with intermediate sizes and clearance rates (i.e., diabodies, minibodies, and single-chain fragment variable $[\mathrm{scFv}]$ fragment crystallizable $[\mathrm{Fc}]$ with molecular weights between 50 to $110 \mathrm{kDa}$ ) may be better suited as imaging agents than full-length IgGs because of their higher penetration capacity into solid tumors (9-11). In addition, intermediate-sized antibody fragments may allow for better imaging results (high signal-to-noise ratio) due to a faster clearance rate from blood and other well-perfused tissues in comparison to whole antibodies, which usually have longer serum half-lives. Therefore, we sought to develop an anti-CD44 antibody using phage display that could be used for PET imaging of CD44-positive cancers.

The aim of our current study was to screen a human $\mathrm{scFv}$ phage display library and identify a novel, high-affinity antibody fragment to CD44 for diagnostic and potentially therapeutic applications. Our $\mathrm{scFv}$ lead was converted into an $\mathrm{scFv}-\mathrm{Fc}$ format and radiolabeled with both ${ }^{64} \mathrm{Cu}$ and ${ }^{89} \mathrm{Zr}$ and evaluated in vitro and in vivo using biodistribution and PET imaging studies. These studies show specific uptake of the scFv-Fc in a CD44-positive tumor model. We believe that, compared with currently explored full-length antibodybased detection and therapy concepts, scFv-based formats offer distinct advantages because of flexibility when it comes to downstream customization tailored toward specific therapeutic goals, such as size variations for superior tumor uptake, half-life alterations, or altered $\mathrm{Fc}$ effector functions through $\mathrm{Fc}$ point mutations.

\section{MATERIALS AND METHODS}

\section{Production of ScFv-Fc Constructs}

The scFv-CD44 was isolated from the WashU-1 phage display library (Supplemental Fig. 1; supplemental materials are available at http://jnm.snmjournals.org) by biopanning against the extracellular domain of recombinant human CD44 (amino acids 21-268) (IT300-001p; Immune Technology Corp.) and the control scFv glycophorin A (GPA) as previously described (12). ScFv-Fcs comprising a C-terminal human $\mathrm{IgG}_{1}-\mathrm{Fc}$ (T106-K330) region were cloned in pYD11 vector and produced by transient HEK293-6E cell expression and purified by protein $\mathrm{G}$ as described before (13). Protein concentrations were characterized by sodium dodecyl sulfate-polyacrylamide gel electrophoresis using a XCell SureLock Mini-Cell system with NuPAGE 4\%-12\% Bis-Tris gels (Thermo Fisher Scientific) and Western blot using a Trans-Blot SD Semi-Dry Transfer Cell (Bio-Rad). Fast protein liquid chromatography analysis was done on an ÄKTA pure protein purification system (GE Healthcare) using a Superdex 200 Increase $10 / 300$ GL column and $20 \mathrm{mM}$ Tris, $150 \mathrm{mM} \mathrm{NaCl}, \mathrm{pH} 8$, as running buffer.

\section{Saturation Binding Studies}

The affinities of the antibody fragments were determined from equilibrium binding curves $\left(\mathrm{EC}_{50} \mathrm{~s}\right)$ generated by flow cytometry as described before (14) by staining of $3 \times 10^{5}$ MDA-MB-231 cells per well. ScFv-CD44 binding was detected by primary murine monoclonal antibody 9E10 $(7.5 \mu \mathrm{g} / \mathrm{mL})$ and secondary goat antimouse polyclonal antibody fluorescein isothiocyanate conjugate (115-095-008; Jackson ImmunoResearch). The scFv-Fc-CD44 was detected by a rabbit antihuman polyclonal antibody fluorescein isothiocyanate conjugate (309-095-008; Jackson ImmunoResearch). To measure the affinities by enzyme-linked immunosorbent assay, MaxiSorp plates (Thermo Fisher Scientific) were coated with CD44 (amino acids 21-268) (3 $\mu \mathrm{g} / \mathrm{mL}$ in $2 \%$ milk in phosphate-buffered saline [PBS]). Serial dilutions (1:2) of the antibody fragments in milk in PBS were incubated in milk-in-PBS-blocked plates in triplicates. The scFv-CD44 was detected with primary murine monoclonal antibody 9E10 $(7.5 \mu \mathrm{g} / \mathrm{mL})$ and secondary goat antimouse polyclonal antibody peroxidase conjugate (115-035-008; Jackson ImmunoResearch). The scFv-FcCD44 was detected by a goat antihuman polyclonal antibody peroxidase conjugate (109-035-098; Jackson ImmunoResearch). 3,3',5,5'-Tetramethylbenzidine substrate solution (Thermo Fisher Scientific) was added to PBS-washed plates and the reaction stopped with $2 \mathrm{M}$ $\mathrm{H}_{2} \mathrm{SO}_{4}$ before reading the absorbance at $450 \mathrm{~nm}$ in a BioTek ELx800 microplate reader. Background signals were subtracted from the measured absorbance (enzyme-linked immunosorbent assay) or median fluorescence intensities (flow), and relative affinities were calculated by nonlinear regression using Prism, version 8 (GraphPad Software).

\section{Radiolabeling and Characterization}

Briefly, scFv-Fcs were conjugated with NOTA (B605) or 1-(4isothiocyanatophenyl)-3-[6,17-dihydroxy-7,10,18,21-tetraoxo-27-( $N$ acetylhydroxylamino)-6,11,17,22-tetraazaheptaeicosine]thiourea (DFO) (B705) from Macrocyclics in a 1:5 molar ratio in $0.1 \mathrm{M}$ carbonate buffer $\left(\mathrm{pH} \mathrm{9.0)}\right.$ for $1 \mathrm{~h}$ at $37^{\circ} \mathrm{C}$. The conjugates were bufferexchanged (NOTA-scFv-Fc: $0.1 \mathrm{M} \mathrm{NH}_{4} \mathrm{OAc}$, pH 6.0; DFO-scFv-Fc: $1 \mathrm{M}$ 4-(2-hydroxyethyl)-1-piperazineethanesulfonic acid, $\mathrm{pH}$ 7.2) and frozen until radiolabeling. The number of chelates per $\mathrm{scFv}-\mathrm{Fc}$ were determined by mass spectrometry as described in the supplemental data. Radiolabeling was performed for $1 \mathrm{~h}$ at $37^{\circ} \mathrm{C}$ using $200 \mu \mathrm{g}$ of conjugated scFv-Fc and $18.5 \mathrm{MBq}(500 \mu \mathrm{Ci})$ of ${ }^{64} \mathrm{Cu}$ or ${ }^{89} \mathrm{Zr}$.

\section{Cell Culture}

All human cancer cell lines were purchased from the American Type Culture Collection and cultivated in complete growth medium (Dulbecco modified Eagle medium supplemented with $10 \mathrm{mM}$ 4-(2-hydroxyethyl)1-piperazineethanesulfonic acid and $10 \%$ heat-inactivated fetal bovine serum) in low passage number in a humidified cell incubator $\left(5 \% \mathrm{CO}_{2}\right.$, $\left.37^{\circ} \mathrm{C}\right)$.

\section{In Vivo Biodistribution Studies}

Animal experiments were conducted in compliance with the Guidelines for Care and Use of Research Animals established by the Washington University Animal Studies Committee using a protocol approved by the committee. The 5- to 6-wk-old female NCI athymic NCr-nu/nu mice (strain 553) ( $n=4-5$ per group) were purchased from Charles River and housed under pathogen-free conditions in the Washington University School of Medicine animal facility. Mice were anesthetized by inhalation of $2 \%$ isoflurane in $100 \%$ oxygen. MDA-MB-231 cells were harvested by trypsinization at $80 \%$ confluency, washed twice (PBS), and implanted subcutaneously on the right shoulder with $1.0 \times 10^{7}$ MDA-MB-231 cells in $100 \mu \mathrm{L}$ of $\mathrm{PBS} / \mathrm{mouse}$. Tumors grew for $2 \mathrm{wk}$, reaching a final mean weight of $123.8 \pm 18.9 \mathrm{mg}( \pm \mathrm{SE})$. In vivo biodistribution studies were conducted in the Washington University Small Animal Imaging Facility. Isoflurane-anesthetized mice were injected via the tail vein with 0.37 MBq $(10 \mu \mathrm{Ci})$ of radiolabeled scFv-Fc targeting either human CD44 or GPA. At the designated time points, mice were sacrificed, tumors and selected organs were collected and weighed, and activity was 
counted with a Beckman Gamma-8000 counter. Tumor and organ uptake were analyzed and calculated as percentage injected dose per gram $(\%$ ID/g). Tumor-to-organ ratios were calculated independently for each mouse on the basis of $\% \mathrm{ID} / \mathrm{g}$ and reported as mean $\pm \mathrm{SE}$. $\left[{ }^{89} \mathrm{Zr}\right] \mathrm{Zr}-$ DFO-scFv-Fc-CD44 was also evaluated in mice bearing PC-3 tumors ( $n$ $=5$ per group) expressing lower levels of CD44 and in non-tumorbearing mice $(n=5)$ to determine the blood half-life as described in the supplemental data.

\section{Small-Animal PET Imaging}

Small-animal PET/CT imaging studies were conducted at the Washington University School of Medicine using the MDA-MB-231 mouse model described above. About $2.22 \mathrm{MBq}(60 \mu \mathrm{Ci})$ of the $\left[{ }^{89} \mathrm{Zr}\right]$ $\mathrm{Zr}-\mathrm{DFO}-\mathrm{scFv}-\mathrm{Fc}$ targeting CD44 or GPA was administrated to mice ( $n=2$ for each construct) via tail vein injection. The mice were anesthetized using $2 \%$ isoflurane in oxygen and imaged using an Inveon small-animal PET/CT imaging system (Siemens) at days 1 and 7 after administration. Static images were collected for $30 \mathrm{~min}$ and reconstructed with a maximum a posteriori probability algorithm followed by CT coregistration using the Inveon Research Workstation image display software (Siemens). The SUVs were calculated by image analysis of muscle and tumor using the decay-corrected concentrations of injected radioactivity and animal weight. Regions of interest were selected from transaxial PET images at the location corresponding to the CT anatomic location of tumors, and the associated activity was measured using Inveon Research Workstation software. The SUV was calculated as the regional activity concentration $(\mathrm{Bq} / \mathrm{cc}) \times$ animal weight $(\mathrm{g}) /$ decay-corrected amount of injected dose $(\mathrm{Bq})$.

\section{Statistics}

Prism, version 8, was used for statistical analyses. Data are represented as the mean \pm SE. Biodistribution data were analyzed by multiple comparison via 1-way ANOVA, followed by the Tukey multiple comparison test. $P$ values of less than 0.05 were considered statistically significant.

\section{RESULTS}

\section{Antibody Generation}

A description of the generation of the human $\mathrm{scFv}$ phage display library is provided in Supplemental Figure 1. Biopanning against the extracellular domain of recombinant human CD44 (amino acids 21-268) resulted in the isolation of a $\mathrm{scFv}$ lead candidate. The yield of the scFv-CD44 after purification was 3.3 $\mathrm{mg} / \mathrm{L}$ of culture bacteria with high purity $(>98 \%)$ (Supplemental Fig. 2) (15). A truncated version of human CD44 (amino acids 21220) was expressed and purified to demonstrate binding of different recombinant formats and to demonstrate no cross-reactivity toward murine CD44, despite sharing $76 \%$ sequence homology on the amino acid level, or other proteins (Supplemental Figs. 3 and 4).

\section{Epitope Mapping}

A peptide microarray identified a single, linear binding epitope of scFv-CD44 comprising the consensus sequence TNPEDIYPS, which is encoded by exon 5 of the CD44 gene (Supplemental Fig. 5). This motif corresponds to region T163-S171 that is conserved in most human CD44 isoforms but only shares $56 \%$ homology with the corresponding mouse homolog (THQEDIDAS). This membrane-distal region of the extracellular domain is structurally close to a region involved in HA binding (Supplemental Fig. 6). Blocking studies confirmed that binding of HA to recombinant human CD44 can be efficiently inhibited by the scFv-Fc-CD44 $\left(\mathrm{IC}_{50}=2.1 \mathrm{nM}\right)($ Supplemental Fig. 7).

\section{Affinity}

The affinity of monovalent scFv-CD44 toward recombinant human CD44 (amino acids 21-268) was determined by generating enzyme-linked immunosorbent assay-based $\mathrm{EC}_{50} \mathrm{~s}$ of $26.3 \pm 5.3$ nM (Table 1). Specificity to tumor cell-expressed CD44 was tested by flow cytometry using human tumor cell lines with different CD44 expression levels including the breast cancer cell line MDA-MB-231 (Supplemental Fig. 8). However, the $\mathrm{EC}_{50}$ of the monovalent scFv-CD44 toward this cell line was reduced compared with recombinant CD44. The analysis of the saturation binding curve by flow cytometry revealed a reduction of $\mathrm{EC}_{50}$ by approximately 20 -fold $(512.4 \pm 50.5 \mathrm{nM})$ (Table 1$)$. To increase the functional affinity, we cloned the monovalent scFv-CD44 into a bivalent scFv-Fc-CD44 format comprising a C-terminal human $\mathrm{IgG}_{1}-\mathrm{Fc}$ (T106-K330) region. Transient expression of the scFv-Fc-CD44 in HEK293-6E suspension culture revealed high yield $(45.6 \mathrm{mg} / \mathrm{L})$ and excellent purity $(>98 \%)$ after only a 1-step protein $\mathrm{G}$ purification procedure, confirmed by sodium dodecyl sulfate-polyacrylamide gel electrophoresis and Western blot analysis (Supplemental Fig. 9). Fast protein liquid chromatography analysis resulted in a main single peak and confirmed the primarily monomeric state of native scFv-Fc-CD44 (94\%). Compared with the monovalent scFv-CD44, the avidity of bivalent scFv-Fc-CD44 to human CD44 (amino acids 21-268) increased approximately 40 -fold $\left(\mathrm{EC}_{50}=0.7 \pm 0.1 \mathrm{nM}\right)$ (Table 1). Importantly, the avidity improved nearly 200-fold on CD44-expressing human MDA-MB-231 breast cancer cells using flow cytometry $\left(\mathrm{EC}_{50}, 2.3 \pm 0.2 \mathrm{nM}\right)$ (Table 1).

\section{Radiolabeling and In Vitro Characterization}

The scFv-Fc-CD44 was conjugated with either NOTA or DFO resulting in a NOTA:scFv-Fc-CD44 ratio of $0.30 \pm 0.02$ and a DFO:scFv-Fc-CD44 ratio of $0.58 \pm 0.06$ (Supplemental Fig. 10), followed by radiolabeling with ${ }^{64} \mathrm{Cu}$ and ${ }^{89} \mathrm{Zr}$, respectively (Supplemental Fig. 11) (16-18). The radiochemical purity of the final products was more than $99.9 \%$ for both the $\left[{ }^{64} \mathrm{Cu}\right] \mathrm{Cu}-\mathrm{NOTA}$ scFv-Fc and the [ $\left.{ }^{89} \mathrm{Zr}\right] \mathrm{Zr}-\mathrm{DFO}-\mathrm{scFv}-\mathrm{Fc}$ (Table 2). The specific activity was $84.7 \pm 11.0 \mathrm{MBq} / \mathrm{mg}$ for $\left[{ }^{64} \mathrm{Cu}\right] \mathrm{Cu}-\mathrm{NOTA}-\mathrm{scFv}-\mathrm{Fc}-$ $\mathrm{CD} 44$ and $80.0 \pm 5.5 \mathrm{MBq} / \mathrm{mg}$ for $\left[{ }^{89} \mathrm{Zr}\right] \mathrm{Zr}-\mathrm{DFO}-\mathrm{scFv}-\mathrm{Fc}$, with labeling yields of $60 \%$ and $75 \%$, respectively (Table 2). The immunoreactive fractions were $88.1 \% \pm 3.7 \%\left({ }^{64} \mathrm{Cu}\right)$ and $87.9 \% \pm 1.9 \%$

\section{TABLE 1}

Affinity of Human Antibody Lead as Recombinant scFv-CD44 or scFv-Fc-CD44

\begin{tabular}{ccc}
\hline Test & scFv-CD44 & scFv-Fc-CD44 \\
\hline ELISA $(n=3)$ & & \\
EC $_{50} \pm$ SE $(n M)$ & $26.3 \pm 5.3$ & $0.7 \pm 0.1$ \\
$R^{2}$ & 0.927 & 0.923 \\
Flow cytometry $(n=3)$ & & \\
EC $_{50} \pm$ SE $(n M)$ & $512.4 \pm 50.5$ & $2.3 \pm 0.2$ \\
$R^{2}$ & 0.970 & 0.985
\end{tabular}

$\mathrm{EC}_{50}$ was calculated from equilibrium-binding curves toward recombinant human CD44 (amino acids 21-268) by enzyme-linked immunosorbent assay (ELISA) and by flow cytometry on MDAMB-231 tumor cells. 
TABLE 2

Characteristics of scFv-Fc-CD44 After Radiolabeling With ${ }^{64} \mathrm{Cu}\left(\left[{ }^{64} \mathrm{Cu}\right] \mathrm{Cu}-\mathrm{NOTA}-\mathrm{scFv}-\mathrm{Fc}-\mathrm{CD} 44\right)$ or ${ }^{89} \mathrm{Zr}\left(\left[{ }^{89} \mathrm{Zr}\right] \mathrm{Zr}-\mathrm{DFO}-\mathrm{scFv}-\mathrm{Fc}-\mathrm{CD} 44\right)$

\begin{tabular}{|c|c|c|c|}
\hline Parameter & $n$ & {$\left[{ }^{64} \mathrm{Cu}\right] \mathrm{Cu}-\mathrm{NOTA}-\mathrm{scFv}-\mathrm{Fc}-\mathrm{CD} 44$} & [89ZZ]Zr-DFO-scFv-Fc-CD44 \\
\hline ITLC (\% region of interest) & 3 & $100.00 \pm 0.0$ & $99.9 \pm 0.0$ \\
\hline Specific activity & 3 & & \\
\hline $\mathrm{MBq} / \mathrm{mg}$ & & $84.7 \pm 11.0$ & $80.0 \pm 5.5$ \\
\hline $\mathrm{mCi} / \mathrm{mg}$ & & $2.3 \pm 0.3$ & $2.2 \pm 0.1$ \\
\hline Labeling efficiency (\%) & 3 & $59.6 \pm 3.5$ & $75.0 \pm 7.1$ \\
\hline Immunoreactivity (\%) & ${ }^{64} \mathrm{Cu}, 2 ;{ }^{89} \mathrm{Zr}, 3$ & $88.1 \pm 3.7$ & $87.9 \pm 1.9$ \\
\hline Blocking efficiency (\%) & ${ }^{64} \mathrm{Cu}, 2 ;{ }^{89} \mathrm{Zr}, 3$ & $99.8 \pm 0.0$ & $97.5 \pm 0.5$ \\
\hline Internalization: specific half-life (min) & ${ }^{64} \mathrm{Cu}, 2 ;{ }^{89} \mathrm{Zr}, 3$ & $57.8 \pm 34.9$ & $56.4 \pm 6.1$ \\
\hline Data are mean \pm SE. & & & \\
\hline
\end{tabular}

$\left({ }^{89} \mathrm{Zr}\right)$ (Table 2, Supplemental Fig. 12A) (19). Binding specificity was confirmed by blocking experiments with native $\mathrm{scFv}$ Fc-CD44, achieving more than 97\% signal reduction (Table 2; Supplemental Fig. 12B). The specific half-lives of internalization into MDA-MB-231 cells was determined to be $57.8 \pm 34.9 \mathrm{~min}$ $\left({ }^{64} \mathrm{Cu}\right)$ and $56.4 \pm 6.1 \mathrm{~min}\left({ }^{89} \mathrm{Zr}\right)$, respectively (Table 2; Supplemental Fig. 12C) (20). Serum stability showed that both $\left[{ }^{64} \mathrm{Cu}\right] \mathrm{Cu}-\mathrm{NOTA}-\mathrm{scFv}-\mathrm{Fc}-\mathrm{CD} 44$ and $\left[{ }^{89} \mathrm{Zr}\right] \mathrm{Zr}-\mathrm{DFO}-\mathrm{scFv}-\mathrm{Fc}-$ CD44 were more than $93 \%$ intact over the time course studied (Supplemental Fig. 13).

\section{Biodistribution Studies}

Biodistribution studies were conducted on mice bearing subcutaneous MDA-MB-231 tumor (Fig. 1; Supplemental Tables 1-4). Tumor uptake of the radiolabeled scFv-Fcs-CD44 increased over time from $3.3 \pm 0.3 \% \mathrm{ID} / \mathrm{g}\left(\left[{ }^{64} \mathrm{Cu}\right] \mathrm{Cu}-\mathrm{NOTA}-\mathrm{scFv}-\mathrm{Fc}\right)$ after $1 \mathrm{~h}$ up to $55.5 \pm 8.6 \% \mathrm{ID} / \mathrm{g}\left(\left[{ }^{89} \mathrm{Zr}\right] \mathrm{Zr}-\mathrm{DFO}-\mathrm{scFv}-\mathrm{Fc}\right)$ after day $7(P<$ $0.0001)$. One day after injection, the tumor uptake of both radiolabeled scFv-Fcs-CD44 were comparable $\left({ }^{64} \mathrm{Cu}, 22.7 \% \pm 5.1 \% \mathrm{ID} / \mathrm{g}\right.$; $\left.{ }^{89} \mathrm{Zr}, 33.3 \pm 6.4 \% \mathrm{ID} / \mathrm{g} ; P=0.7979\right)$. In contrast, blood levels declined over time from $20.7 \pm 1.7 \% \mathrm{ID} / \mathrm{g}\left({ }^{64} \mathrm{Cu}\right.$ at day 1) to 2.3 $\pm 0.8 \% \mathrm{ID} / \mathrm{g}\left({ }^{89} \mathrm{Zr}\right.$ at day 7$)$. As a negative control, human GPA-specific scFv-Fc that does not bind to MDA-MB-231 cells was radiolabeled with ${ }^{89} \mathrm{Zr}$ and used (Supplemental Fig. 14). Biodistribution of the scFv-Fc-GPA control revealed reduced tumor uptake that never exceeded $8.1 \pm 1.1 \% \mathrm{ID} / \mathrm{g}$ (Supplemental Table 3 and 4). Evaluation of $\left[{ }^{89} \mathrm{Zr}\right] \mathrm{Zr}-\mathrm{DFO}-\mathrm{scFv}-\mathrm{Fc}-\mathrm{CD} 44$ and [ $\left.{ }^{89} \mathrm{Zr}\right] \mathrm{Zr}$-DFO-scFv-Fc-GPA in mice bearing PC-3 tumors (Supplemental Tables 5 and 6) with a medium level of CD44 expression (Supplemental Fig. 8) showed lower uptake than in the MDA-MB231 xenografts at both $1 \mathrm{~d}(20.7 \pm 2.5$ vs. $33.3 \pm 6.4 \% \mathrm{ID} / \mathrm{g})$ and 7 d $(31.9 \pm 3.1$ vs. $55.5 \pm 8.6 \% \mathrm{ID} / \mathrm{g})$, demonstrating the difference in $\mathrm{CD} 44$ expression. In addition, uptake of $\left[{ }^{89} \mathrm{Zr}\right] \mathrm{Zr}$ DFO-scFv-Fc-GPA was $6.0 \pm 0.3$ and $3.5 \pm 0.1 \% \mathrm{ID} / \mathrm{g}$ at 1 and $7 \mathrm{~d}$, respectively, demonstrating the specificity for CD44. To emphasize the specificity of our scFv-Fc-CD44 in targeting CD44, the tumor-to-organ ratios for the MDA-MB-231 tumors were calculated (Fig. 2; Supplemental Tables 7 and 8) on the basis of the biodistribution data and compared with those for the control (Supplemental Tables 9 and 10). Tumor-to-blood (TTB) ratios increased over time for the scFv-Fc-CD44, with similar ratios after $1 \mathrm{~d}$ for the ${ }^{64} \mathrm{Cu}$-labeled $(2.3 \pm 0.6)$ and ${ }^{89} \mathrm{Zr}$-labeled $(4.5 \pm 1.1)$
scFv-Fc-CD44. The highest TTB ratios were reached after day 5 $(39.3 \pm 9.4)$ and after day $7(35.6 \pm 11.0)$ for ${ }^{89} \mathrm{Zr}$. The highest tumor-to-muscle ratios were observed for $\left[{ }^{89} \mathrm{Zr}\right] \mathrm{Zr}$-DFO-scFv-FcCD44, with $51.8 \pm 7.2(5 \mathrm{~d})$ and $74.2 \pm 5.9(7 \mathrm{~d})$, respectively. For the scFv-Fc control, the TTB and tumor-to-muscle ratios were low, never exceeding $1.4 \pm 0.2\left({ }^{89} \mathrm{Zr}, 7 \mathrm{~d}\right)$ and $5.6 \pm 1.1\left({ }^{89} \mathrm{Zr}, 1\right.$ d), respectively. An increase in bone uptake was measured for the $\left[{ }^{89} \mathrm{Zr}\right] \mathrm{Zr}-\mathrm{DFO}-\mathrm{scFv}-\mathrm{Fc}-\mathrm{CD} 44(11.9 \pm 1.1 \% \mathrm{ID} / \mathrm{g}$ on day 7$)$, not uncommon for ${ }^{89} \mathrm{Zr}$-labeled antibodies. The ratios of ${ }^{64} \mathrm{Cu}-$ labeled and ${ }^{89} \mathrm{Zr}$-labeled scFv-Fc-CD44 to scFv-Fc-GPA in tumors and normal organs are shown in Figure 3 (Supplemental Tables 11 and 12). As expected, the ratios for the normal organs are approximately $1-1.5$, as the uptake of the scFv-Fc-CD44 is not expected to be different from the uptake of the scFv-Fc-GPA since the $\mathrm{scFv}-\mathrm{Fc}-\mathrm{CD} 44$ does not bind to murine CD44. However, at time points of $1 \mathrm{~d}$ or longer, there is clearly specific uptake in the tumor. The blood half-life of [ $\left.{ }^{89} \mathrm{Zr}\right] \mathrm{Zr}-\mathrm{DFO}-\mathrm{scFv}-\mathrm{Fc}-\mathrm{CD} 44$ was determined to be $77.2 \mathrm{~h}$ (Supplemental Fig. 15).

\section{PET Analysis}

On the basis of the higher TTB ratios, in vivo PET imaging was performed for the $\left[{ }^{89} \mathrm{Zr}\right] \mathrm{Zr}-\mathrm{DFO}-\mathrm{scFv}-\mathrm{Fc}-\mathrm{CD} 44$ after day 1 and 7

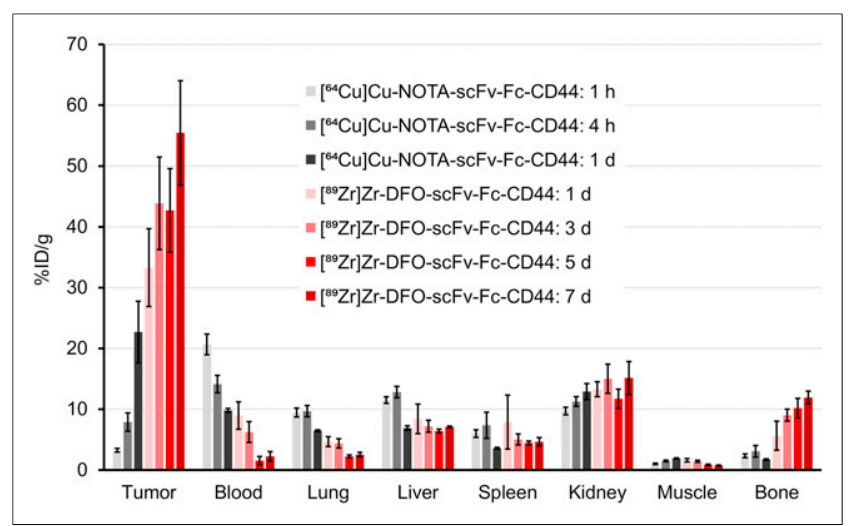

FIGURE 1. In vivo biodistribution of scFv-Fc-CD44. Athymic nude mice bearing MDA-MB-231 tumors were injected intravenously with $0.37 \mathrm{MBq}(10 \mu \mathrm{Ci})$ of either $\left[{ }^{64} \mathrm{Cu}\right] \mathrm{Cu}-\mathrm{NOTA}-\mathrm{scFv}-\mathrm{Fc}-\mathrm{CD} 44(n=5)$ or [99 Zr]Zr-DFO-scFv-Fc-CD44 $(n=4)$ and sacrificed after various time points. Data are expressed as mean $\pm \mathrm{SE}$ of $\% \mathrm{ID} / \mathrm{g}$. 


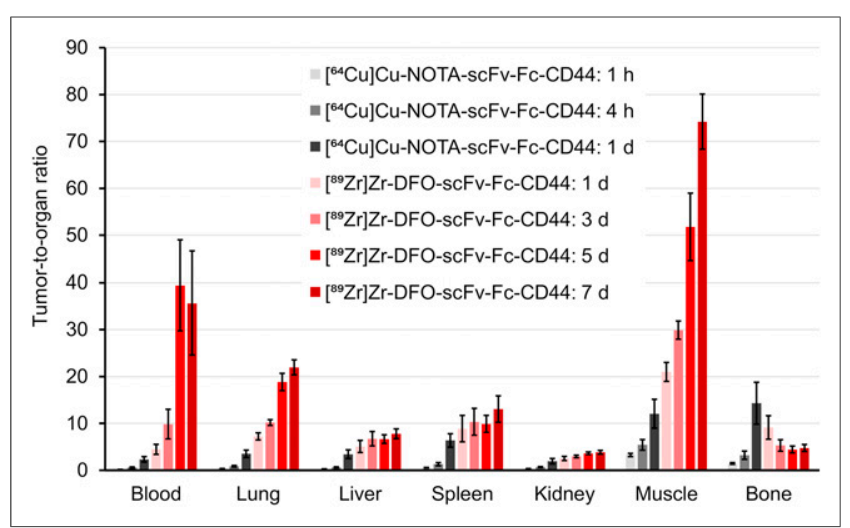

FIGURE 2. Tumor-to-organ ratios of scFv-Fc-CD44. Ratios were calculated separately for each mouse based on \%ID/g data and expressed as mean \pm SE for $\left[{ }^{64} \mathrm{Cu}\right] \mathrm{Cu}-\mathrm{NOTA}-\mathrm{scFv}-\mathrm{Fc}-\mathrm{CD} 44(n=5)$ or $\left[{ }^{89} \mathrm{Zr}\right] \mathrm{Zr}-$ DFO-scFv-Fc-CD44 $(n=4)$.

after injection and compared with the control (Fig. 4A). Tumor uptake of the scFv-Fc-CD44 was visible after $1 \mathrm{~d}$, although background signal in other organs could also be detected. In contrast, high and specific tumor uptake could be detected after $7 \mathrm{~d}$, with almost no remaining background in other organs. For the control, uptake was visible in all highly vascularized tissues, including tumor after $1 \mathrm{~d}$, likely because of high levels in the blood, presumably caused by Fc receptor recycling or an effect known as enhanced permeability and retention. After day 7, however, the control gave only a minor signal for the entire mouse, including a lack of tumor detection. The PET images were further analyzed by calculating $\mathrm{SUV}_{\text {mean }}$ and $\mathrm{SUV}_{\max }$ (Fig. 4B; Supplemental Table 13). In the case of the scFv-Fc-CD44, the SUVs of the tumors were increased after day $7\left(\mathrm{SUV}_{\max }, 20.3 \pm 2.1\right)$ compared with day $1\left(\mathrm{SUV}_{\max }, 12.2 \pm 0.2\right)$. In contrast, much lower uptake in muscle was detected for both day $1\left(\mathrm{SUV}_{\max }, 1.3 \pm 0.2\right)$ and day 7 $\left(\mathrm{SUV}_{\max }, 0.8 \pm 0.2\right)$. For the control, $\mathrm{SUV}_{\max }$ uptake was low in tumor $(1 \mathrm{~d}, 5.6 \pm 0.6 ; 7 \mathrm{~d}, 2.9 \pm 0.5)$ and muscle $(1 \mathrm{~d}, 1.1 \pm 0.1 ; 7 \mathrm{~d}$, $0.7 \pm 0.2)$.

\section{DISCUSSION}

Although CD44 is an attractive target for cancer therapy because of high expression levels on tumor cells, it is also present in

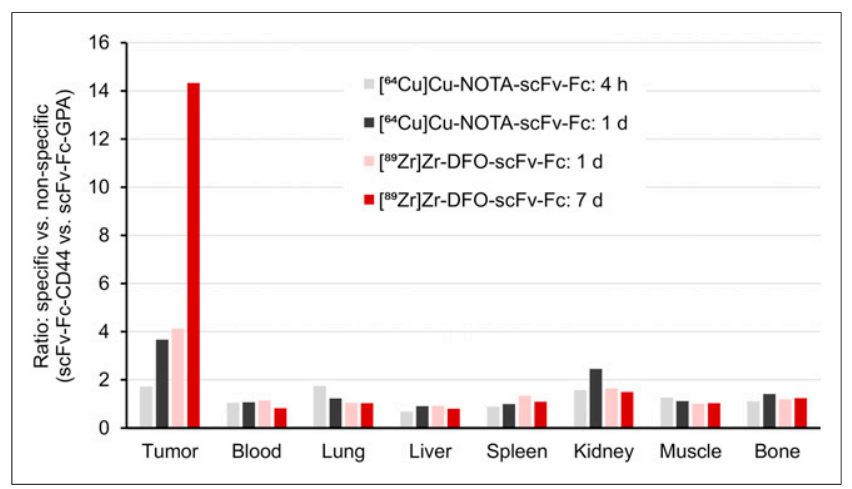

FIGURE 3. Ratios for specific uptake (scFv-Fc-CD44) vs. nonspecific uptake (scFv-Fc-GPA). Ratios are based on average \%ID/g data from biodistribution study in mice with MDA-MB-231 tumor xenografts. normal epithelium. Therefore, noninvasive imaging of its expression in patients will be needed for CD44-directed therapies. Biopsies can provide initial information regarding target expression, but not all lesions are accessible for this procedure and the regions obtained may not be representative of the entire tumor mass because of tissue heterogeneities. Furthermore, expression in distant normal tissue cannot be determined using tumor-directed biopsies. For CD44, radiolabeled antibodies can be used to determine tumor and whole-body expression. Importantly, noninvasive imaging should be able to increase the therapeutic efficacy of antibodies targeting CD44 by determining appropriate doses for tumor accumulation and limiting normal-tissue toxicities. Therefore, the development of an engineered antibody in which in vivo pharmacokinetics can be optimized for noninvasive imaging would be valuable for the development of future CD44-targeted therapeutics.

Here, we report the generation of a human CD44-specific antibody fragment ( $\mathrm{scFv}$ ) using a human scFv-bacteriophage library. To improve its pharmacokinetic properties, we generated a bivalent antibody via incorporation into a human Fc format. Although this reformatting increased the apparent affinity of the molecule to human CD44 as anticipated, it has been shown for different CD44specific monoclonal antibodies that pharmacokinetics plays a more important role in tumor uptake than mere affinities (21). Since we did not know a priori the blood half-life of our scFv-Fc, we radiolabeled our reagents with either ${ }^{64} \mathrm{Cu}$ or ${ }^{89} \mathrm{Zr}$ to investigate short and long time points in vivo, respectively. Our data demonstrate that ${ }^{89} \mathrm{Zr}$ is the appropriate choice for this particular $\mathrm{scFv}-\mathrm{Fc}$ since tumor accumulation and TTB ratios were greatest after 5-7 d. In addition, configuration into the $\mathrm{scFv}$-Fc format resulted in a blood half-life of $77.2 \mathrm{~h}$ for $\left[{ }^{89} \mathrm{Zr}\right] \mathrm{Zr}-\mathrm{scF} v-F c-C D 44$ (Supplemental Fig. 15), which

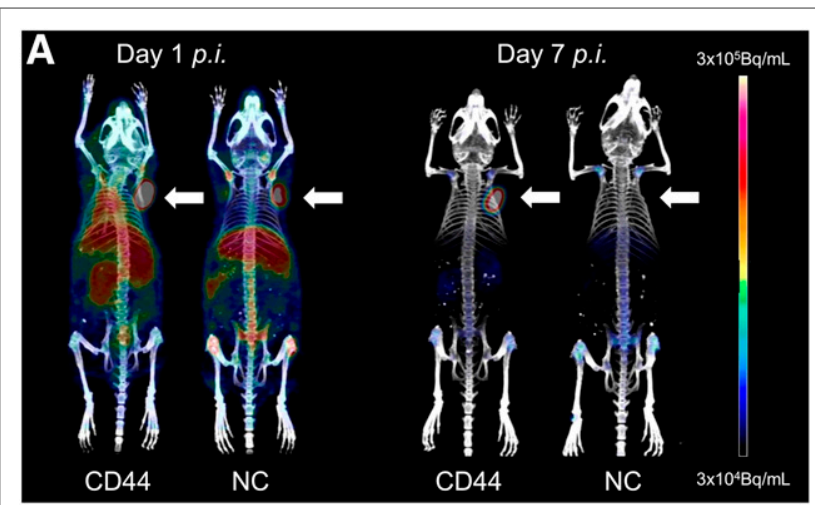

B

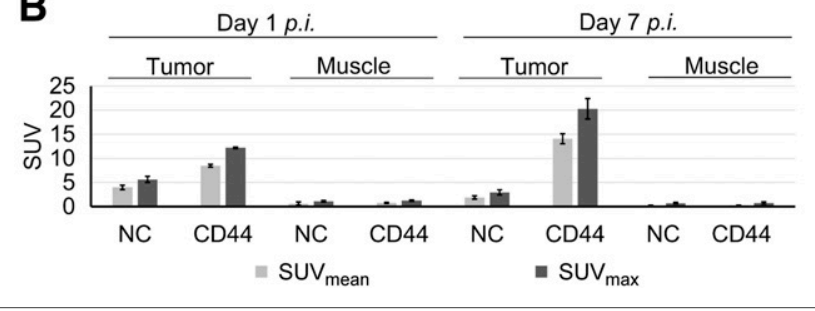

FIGURE 4. (A) Representative PET images 1 and $7 d$ after injection of [ $\left.{ }^{89} \mathrm{Zr}\right] \mathrm{Zr}$-DFO-scFv-Fc-CD44 (left mice) or [ $\left.{ }^{89} \mathrm{Zr}\right] \mathrm{Zr}$-DFO-scFv-Fc-GPA (right mice). Arrows indicate position of MDA-MB-231 tumor xenografts. (B) SUV analysis after injection of [ $\left.{ }^{89} \mathrm{Zr}\right] \mathrm{Zr}$-DFO-scFv-Fc-CD44 $(n=2)$ or [ ${ }^{89} \mathrm{Zr}$ ]Zr-DFO-scFv-Fc-GPA $(n=2) . \mathrm{NC}=$ negative control; p.i. = post injection. 
was shorter than the more than $125 \mathrm{~h}$ reported for $\left[{ }^{89} \mathrm{Zr}\right] \mathrm{Zr}-\mathrm{DFO}-$ RG7356 (6).

A humanized antibody, RG7356, that targets all isoforms of CD44 has been previously studied because it disrupts the binding of HA to CD44, causing anticancer activity (5). This characteristic is distinct from CD44 antibodies that target CD44 variant 6 , in which this interaction is not disrupted. Vugts et al. evaluated $\left[{ }^{89} \mathrm{Zr}\right]$ Zr-DFO-RG7356 in mice bearing MDA-MB-231 xenografts and found that tumor uptake was approximately $30 \% \mathrm{ID} / \mathrm{g}$ at 3-6 $\mathrm{d}$ after injection (6), which is less than our $56 \% \mathrm{ID} / \mathrm{g}$ achieved at $7 \mathrm{~d}$. Similarly, our [ $\left.{ }^{89} \mathrm{Zr}\right] \mathrm{Zr}-\mathrm{scF}$-Fc-CD44 had superior TTB ratios of approximately 36 at 5-7 d, compared with [ ${ }^{89} \mathrm{Zr}$ ]Zr-DFORG7356, which had a ratio of 8.7 at $6 \mathrm{~d}(6)$. Neither RG7356 nor our scFv-Fc binds to murine CD44. Evaluation of [ $\left.{ }^{89} \mathrm{Zr}\right] \mathrm{Zr}-\mathrm{DFO}-$ RG7356 in monkeys showed uptake in the spleen, salivary glands, and bone marrow, which is believed to be CD44-specific. Subsequent clinical evaluation of $\left[{ }^{89} \mathrm{Zr}\right] \mathrm{Zr}-\mathrm{DFO}-\mathrm{RG} 7356$ demonstrated tumor targeting and its ability to quantify dose-dependent uptake in normal tissues $(7,8)$. These results demonstrate the utility of probing CD44 expression in vivo and that our $\mathrm{scFv}-\mathrm{Fc}$ appears to be superior to RG7356 in terms of tumor uptake and TTB ratios in mouse models. However, whereas our mapping studies demonstrate binding of the $\mathrm{scFv}-\mathrm{Fc}$ to the HA binding domain, we have yet to show in vivo therapeutic efficacy using this construct.

Although we have demonstrated that the $\left[{ }^{89} \mathrm{Zr}\right] \mathrm{Zr}-\mathrm{scFv}-\mathrm{Fc}-$ CD44 has good tumor localization, late time points are needed to achieve high TTB and tumor-to-organ ratios. Therefore, future studies will evaluate other antibody formats, such as diabodies and minibodies, shown to achieve faster clearance patterns from blood and normal tissues, thus leading to higher ratios at earlier times. This will allow for labeling options using radionuclides that have shorter half-lives such as ${ }^{64} \mathrm{Cu},{ }^{68} \mathrm{Ga}$, or ${ }^{18} \mathrm{~F}$ and could potentially lead to same-day imaging to determine CD44 expression.

\section{CONCLUSION}

Overall, [ $\left.{ }^{89} \mathrm{Zr}\right] \mathrm{Zr}-\mathrm{DFO}-\mathrm{scFv}-\mathrm{Fc}-\mathrm{CD} 44$ achieved higher TTB and tumor-to-organ ratios at later time points (i.e., days 5 and 7) compared with $\left[{ }^{64} \mathrm{Cu}\right] \mathrm{Cu}-\mathrm{NOTA}-\mathrm{scFv}-\mathrm{Fc}-\mathrm{CD} 44$ at earlier time points (up to $1 \mathrm{~d}$ ). We believe that our engineered $\mathrm{scFv}-\mathrm{Fc}$ is superior to $\left[{ }^{89} \mathrm{Zr}\right] \mathrm{Zr}$-DFO-RG7356 when compared in the same mouse model and could be valuable for PET imaging in patients with CD44-positive malignancies. Future studies are required to determine whether our novel antihuman CD44 scFv-Fc exhibits therapeutic efficacy or if other antibody formats, such as diabodies and minibodies, provide more favorable activity profiles in vivo.

\section{DISCLOSURE}

This work was supported by the Department of Radiation Oncology at Washington University School of Medicine and NIH R21 CA181022-01 (Buck Rogers). No other potential conflict of interest relevant to this article was reported.

\section{ACKNOWLEDGMENTS}

We thank the small-animal imaging facility at Washington University School of Medicine for technical assistance in conducting biodistribution and imaging studies. We acknowledge the isotope production group at Washington University for the production of ${ }^{64} \mathrm{Cu}$ and ${ }^{89} \mathrm{Zr}$. We thank Dr. Brian Mooney from the University of Missouri (Columbia, MO) for performing the mass spectrometry analysis to determine chelate-to-antibody ratios. We acknowledge Dr. Abhay Singh for providing assistance with fast protein liquid chromatography operations and Dr. Heping Yan for providing the anti-Myc monoclonal antibody.

\section{KEY POINTS}

QUESTION: Can an anti-CD44 scFv be isolated from a human phage display library and used to image CD44 expression in a preclinical mouse model?

PERTINENT FINDINGS: The biodistribution of [89Zr]Zr-DFOscFv-Fc-CD44 showed high tumor-specific uptake (up to $56 \%$ ID/ g) in a CD44-expressing xenograft tumor and high TTB (up to 39) and tumor-to-muscle (up to 74 ) ratios compared with a control [ $\left.{ }^{89} \mathrm{Zr}\right] \mathrm{Zr}$-DFO-scFv-Fc-GPA. PET imaging showed good tumor uptake in this model at $7 \mathrm{~d}$, with low background compared with control.

IMPLICATIONS FOR PATIENT CARE: Development of a novel anti-CD44 antibody in which pharmacokinetics can be optimized in the future will lead to a clinical tool for imaging CD44 expression, thus impacting the development of CD44-targeted therapeutics.

\section{REFERENCES}

1. Azevedo R, Gaiteiro C, Peixoto A, et al. CD44 glycoprotein in cancer: a molecular conundrum hampering clinical applications. Clin Proteomics. 2018;15:22.

2. Wang SJ, Wong G, de Heer AM, Xia W, Bourguignon LY. CD44 variant isoforms in head and neck squamous cell carcinoma progression. Laryngoscope. 2009;119: 1518-1530.

3. Orian-Rousseau V, Ponta H. Perspectives of CD44 targeting therapies. Arch Toxicol. 2015;89:3-14

4. Tijink BM, Buter J, de Bree R, et al. A phase I dose escalation study with antiCD44v6 bivatuzumab mertansine in patients with incurable squamous cell carcinoma of the head and neck or esophagus. Clin Cancer Res. 2006;12:60646072 .

5. Weigand S, Herting F, Maisel D, et al. Global quantitative phosphoproteome analysis of human tumor xenografts treated with a CD44 antagonist. Cancer Res. 2012;72:4329-4339.

6. Vugts DJ, Heuveling DA, Stigter-van Walsum M, et al. Preclinical evaluation of ${ }^{89} \mathrm{Zr}$-labeled anti-CD44 monoclonal antibody RG7356 in mice and cynomolgus monkeys: prelude to phase 1 clinical studies. MAbs. 2014;6:567-575.

7. Jauw YWS, Huisman MC, Nayak TK, et al. Assessment of target-mediated uptake with immuno-PET: analysis of a phase I clinical trial with an anti-CD44 antibody. EJNMMI Res. 2018;8:6.

8. Menke-van der Houven van Oordt CW, Gomez-Roca C, van Herpen C, et al. First-in-human phase I clinical trial of RG7356, an anti-CD44 humanized antibody, in patients with advanced, CD44-expressing solid tumors. Oncotarget. 2016;7:80046-80058.

9. Kenanova V, Olafsen T, Crow DM, et al. Tailoring the pharmacokinetics and positron emission tomography imaging properties of anti-carcinoembryonic antigen single-chain Fv-Fc antibody fragments. Cancer Res. 2005;65:622631 .

10. Sundaresan G, Yazaki PJ, Shively JE, et al. ${ }^{124} \mathrm{I}$-labeled engineered antiCEA minibodies and diabodies allow high-contrast, antigen-specific small-animal PET imaging of xenografts in athymic mice. J Nucl Med. 2003;44:19621969.

11. Thurber GM, Schmidt MM, Wittrup KD. Antibody tumor penetration: transport opposed by systemic and antigen-mediated clearance. Adv Drug Deliv Rev. 2008;60:1421-1434.

12. Spitzer D, Mitchell LM, Atkinson JP, Hourcade DE. Properdin can initiate complement activation by binding specific target surfaces and providing a platform for de novo convertase assembly. J Immunol. 2007;179:2600-2608. 
13. Diebolder P. "LYmph Node Derived Antibody Libraries" (LYNDAL): a concept for recovering human monoclonal antibodies with therapeutic potential [dissertation]. University of Stuttgart; 2014.

14. Diebolder P, Keller A, Haase S, et al. Generation of "LYmph Node Derived Antibody Libraries" (LYNDAL) for selecting fully human antibody fragments with therapeutic potential. MAbs. 2014;6:130-142.

15. Diebolder P, Krawczyk A. Detailed protocols for the selection of antiviral human antibodies from combinatorial immune phage display libraries. In: Bölkicke T, ed. Antibody Engineering. London, U.K.: IntechOpen; 2018:75-102.

16. Diebolder P, Vazquez-Pufleau M, Bandara N, et al. Aerosol-synthesized siliceous nanoparticles: impact of morphology and functionalization on biodistribution. Int J Nanomedicine. 2018;13:7375-7393.

17. Kume M, Carey PC, Gaehle G, et al. A semi-automated system for the routine production of copper-64. Appl Radiat Isot. 2012;70:1803-1806.
18. Wooten AL, Madrid E, Schweitzer GD, et al. Routine production of ${ }^{89} \mathrm{Zr}$ using an automated module. Appl Sci (Basel). 2013;3:593-613.

19. Lindmo T, Boven E, Cuttitta F, Fedorko J, Bunn PA Jr. Determination of the immunoreactive fraction of radiolabeled monoclonal antibodies by linear extrapolation to binding at infinite antigen excess. J Immunol Methods. 1984; 72:77-89.

20. Craft JM, De Silva RA, Lears KA, et al. In vitro and in vivo evaluation of a ${ }^{64} \mathrm{Cu}$-labeled NOTA-Bn-SCN-Aoc-bombesin analogue in gastrin-releasing peptide receptor expressing prostate cancer. Nucl Med Biol. 2012;39:609616.

21. Glatt DM, Beckford Vera DR, Parrott MC, Luft JC, Benhabbour SR, Mumper RJ. The interplay of antigen affinity, internalization, and pharmacokinetics on CD44positive tumor targeting of monoclonal antibodies. Mol Pharm. 2016;13:18941903 